\title{
Analisis Komunikasi Krisis Dicabutnya Sertifikasi Halal Toko Roti BreadTalk
}

\author{
Intan Primasari* \\ Universitas Muhammadiyah Bandung \\ Email: primasari.intan@gmail.com* \\ *corresponding author
}

Keywords:

Communications crisis

halal certificate

BreadTalk

Kata Kunci:

Krisis komunikasi

sertifikat halal

BreadTalk

\begin{abstract}
Crisis can strike anytime and anywhere. It can happen to any company or organization unavoidably. With a good management, crisis can help company step up the reputation. BreadTalk, a Singaporean multinational food and beverage corporation that have opened numerous outlets nationwide, had obtained halal certificate issued by Majelis Ulama Indonesia in 2011. However, the certificate has not been renewed after its expiration. This research aims to study the actions taken by BreadTalk against crisis that attributed to the halal certificate revocation by Majelis Ulama Indonesia.
\end{abstract}

\begin{abstract}
ABSTRAK
Krisis dapat terjadi dimana saja dan kapan saja serta pada siapa saja. Krisis bisa datang tanpa kesiapan dari perusahaan. Krisis jika dikelola dengan baik akan dapat meningkatkan reputasi perusahaan namun juga berlaku sebaliknya. BreadTalk, toko roti asal Singapura yang membuka cabangnya di Indonesia pernah mendapatkan sertifikasi halal dari Majelis Ulama Indonesia pada tahun 2011. Namun saat masa berlaku habis, pihak BreadTalk tidak memperpanjang sertifikat tersebut. Penelitian ini bertujuan untuk mengetahui bagaimana tindakan BreadTalk Indonesia menangani krisis yang disebabkan oleh dicabutnya sertifikasi halal produk BreadTalk oleh MUI.
\end{abstract}

Copyright (C) 2018 Channel Jurnal Komunikasi. All right reserved.

\section{PENDAHULUAN}

Perkembangan pasar tak dipungkiri membuat banyaknya produk asing yang datang dan berinvestasi di Indonesia. Indonesia menjadi pasar yang menjanjikan bagi para investor untuk menanamkan modal. Terlebih ketika dimulainya MEA (Masyarakat Ekonomi Asean) dimana antar negara ASEAN bebas dalam memasarkan produk. Hal tersebut menimbulkan imbas pula terhadap dunia kuliner yang persaingannya menjadi semakin ketat. Menuntut pihak produsen agar selalu menjaga kualitas dan kepercayaan konsumen atas produknya.

BreadTalk adalah toko roti asal Singapura yang memiliki cabang di Asia Tenggara dan Timur Tengah. BreadTalk yang didirikan pada tanggal 6 Maret 2003 oleh George Quek, membuka outlet di luar Singapura di antaranya : Indonesia, Hong Kong, China Filipina, Malaysia, Vietnam, Thailand, India, Korea Selatan, Bahrain, Oman, Kuwait, dan Arab Saudi.

Di Indonesia, BreadTalk menjadi sangat populer karena rasa dan kualitasnya yang sangat terjamin. Beragam pilihan serta harganya yang cukup terjangkau menjadikan BreadTalk cukup digemari sebagian besar masyarakat Indonesia. Sayangnya, produk tersebut sampai saat ini belum memiliki sertifikat halal. Pada tahun 2011, LPPOM MUI pernah mengeluarkan sertifikat halal untuk BreadTalk Indonesia, tapi setelah masa berlakunya habis, pihak BreadTalk tidak mau memperpanjangnya. Masyarakat Indonesia yang mayoritas beragama Islam menjadi enggan dan khawatir untuk mengkonsumsi BreadTalk. Hal ini berpengaruh pada menurunnya omzet BreadTalk dan beberapa gerai BreadTalk terpaksa harus ditutup. 
Menurut Undang-Undang Republik Indonesia Nomor 33 Tahun 2014 tentang jaminan produk halal, dimana sudah ada aturan yang sah tentang produk yang beredar di Indonesia harus sudah mendapat sertifikat halal, untuk memberikan kenyamanan, keamanan, keselamatan, dan kepastian ketersediaan produk halal bagi masyarakat dalam mengonsumsi dan menggunakan produk. Selain itu aturan pemasaran makanan di Indonesia juga diatur oleh BPOM, dimana mereka yang berhak menjamin tentang kualitas makanan yang beredar di Indonesia.

Pihak BreadTalk gagal mendapatkan sertifikat halal karena tidak dapat memberikan data-data yang dibutuhkan dalam kepentingan sertifikasi halal, sehingga masih dipertanyakan kehalalannya.

Pemberitaan ini ternyata sangat berdampak pada keputusan pembelian konsumen terhadap produk BreadTalk. Kurangnya kepercayaan konsumen terkait perusahaan yang belum memiliki sertifikat halal MUI. Hal ini tentunya akan menguntungkan bagi pesaing BreadTalk yang sudah memiliki sertifikat halal karena masyarakat cenderung memilih produk yang sudah memiliki label halal.

Tentu saja ini menuntut seorang public relations officer harus merespon dengan cepat situasi krisis yang terjadi. Di sinilah komunikasi krisis berperan. Werner (1990, dalam Millar \& Heath, 2004) berpendapat bahwa ketika krisis mulai meningkat, hal yang paling penting untuk dilakukan adalah komunikasi. Pendapat lain dari Coombs (dikutip dari Kyhn, 2008) mengungkapkan bahwa krisis komunikasi merupakan “darah kehidupan” bagi seluruh aktivitas manajemen krisis dan memainkan peran penting di manajemen krisis. Sebuah tindakan yang cepat dan efektif harus dilakukan oleh perusahaan ketika menghadapi apapun problem yang dihadapi. Segera memberikan pesan yang akan disampaikan, sebab membiarkan rumor beredar secara liar hanya akan menambah kesulitan bagi organisasi (Millar \& Heath, 2004).

\section{a. Rumusan Masalah}

Permasalahan tersebut dirumuskan dalam pertanyaan sebagai berikut : "Bagaimanakah tindakan BreadTalk Indonesia dalam menghadapi Krisis yang disebabkan oleh dicabutnya sertifikat halal oleh MUI?".

\section{b. Tujuan Penelitian}

Adapun tujuan dari penelitian ini meliputi :

1. Tujuan Umum

Untuk mengkaji berbagai teori komunikasi krisis dan pengaplikasiannya pada kasus BreadTalk Indonesia.

2. Tujuan Khusus

Untuk mengetahui dan menganalisis secara mendalam mengenai dampak dari komunikasi krisis terhadap perusahaan.

\section{c. Kegunaan Penelitian}

Penelitian ini diharapkan dapat memberikan kegunaan bagi :

1. Aspek Pengembangan Ilmu

Pengembangan ilmu komunikasi, khusunya dalam bidang public relations, dalam bentuk strategi komunikasi krisis dan pengaruh komunikasi krisis terhadap perusahaan.

2. Aspek Praktis

Hasil penelitian ini diharapkan dapat bermanfaat bagi public relations officer atau petugas humas BreadTalk Indonesia agar dapat dikaji untuk kepentingan perusahaan dikemudian hari.

\section{TINJAUAN PUSTAKA}

1. Komunikasi Krisis

Menurut Coombs dalam Health \& O’Hair 2009, krisis adalah hal yang dimengerti sebagai persepsi mengenai kejadian yang mengancam harapan penting dari para pemangku kepentingan dan dapat memengaruhi kinerja organisasi. Komunikasi krisis meneliti bagaimana pengumpulan, pengolahan, dan penyebaran informasi yang diperlukan untuk menghadapi keadaan krisis.

Dalam kasus ini, perusahaan BreadTalk mengalami situasi krisis yaitu perusahaan BreadTalk yang belum mendapatkan sertifikasi halal dari MUI dan diduga bahwa perusahaan tersebut tidak memenuhi persyaratan untuk mengumpulkan data-data yang dibutuhkan untuk mendapatkan sertifikat tersebut. Hal ini menimbulkan keraguan dan menghilangkan kepercayaan para konsumn BreadTalk.

2. Elemen Komunikasi Krisis

Berikut merupakan elemen komunikasi krisis pada perusahaan BreadTalk yang belum mendapatkan sertifikasi halal yaitu: 
a) Tiba-tiba

Perusahaan BreadTalk mengalami situasi krisis secara tiba-tiba yaitu pada saat sertifikasi halal perusahaan BreadTalk telah berakhir namun pihak BreadTalk tidak dengan segera memperpanjang sertifikasi halal tersebut sehingga hal tersebut menjadi pemicu terjadinya krisis.

b) Ancaman

Pada saat perusahaan BreadTalk belum memperpanjang sertifikasi halal dan hal tersebut diketahui oleh media dan tersebar kepada masyarakat, hal tersebut menjadi ancaman bagi perusahaan.

c) Berdampak

Situasi krisis yang dialami oleh perusahaan BreadTalk dan diketahui oleh masyarakat berdampak buruk bagi reputasi perusahaan hingga akhirnya menghentikan kepercayaan konsumen terhadap BreadTalk.

3. Tahapan Komunikasi Krisis

Dalam kasus ini BreadTalk melakukan tahapan - tahapan dalam menangani kasus krisis tersebut. Tahapan tahapan yang dilakukan adalah :

a) Pre-Crisis

Tahapan ini merupakan kondisi sebelum krisis muncul dan telah ada benih krisis sebelumnya namun belum terdeteksi. Perusahaan tidak memiliki perencanaan menghadapi krisis.

b) Tahap Warning

Tahapan ini merupakan tahapan yang paling penting dalam krisis. Pada saat ini barulah muncul masalah krisis. Reaksi perusahaan yaitu kaget tapi pura-pura merasa aman. Perusahaan mengenali masalah dan mencari solusi dan berusaha menyelesaikan dan tidak boleh dibiarkan berkembang menjadi krisis yang lebih besar.

c) Tahap Acute Crisis

Pada tahapan ini masalah krisis sudah mulai diketahui oleh media luar dan masyarakat. Perusahaan harus membuat TMK (Tim Manajemen Krisis).

d) Tahap Clean Up

Tahapan ini merupakan tahapan dimana perusahaan memulihkan dari kerugian dan mencoba menyelamatkan apa saja yang tersisa yaitu produk dan reputasi. Hal yang dihadapi perusahaan yaitu hukum, media, dan tekanan publik. Menjadi pelajaran tentang semua yang telah dilakukan sebagai pelajaran agar krisis tidak terulang.

e) Tahap Post Crisis

Pada tahapan ini perusahaan berusaha untuk memenangkan kembali kepercayaan konsumen dan meningkatkan citra baik perusahaan. Hal yang dapat dilakukan perusahaan antara lain adalah kampanye promosi.

\section{Karakteristik Komunikasi Krisis}

\section{a) Unexpected}

Pada kasus ini adalah permasalahan tentang belum diperpanjangnya sertifikat halal oleh MUI.

\section{b) Non Routine}

Kejadian ini tidaklah terjadi secara rutin, lebih kepada permasalahan yang muncul dikarenakan belum selesainya masalah tentang pengurusan sertifikat halal BreadTalk.

c) Produce Uncertainty

Menciptakan suatu ketidakpastian yang membuat dampak negatif terhadap pandangan masyarakat, karena pihak BreadTalk sendiri belum memberi konfirmasi secara resmi.

d) Create Opportunity

Menciptakan peluang, dimana seharusnya BreadTalk bertindak secara cepat untuk menyelesaikan sertifikasinya. Sehingga masyarakat yang sudah terlanjur fokus untuk memberitakan hal negatif akan tergantikan menjadi rasa percaya pada BreadTalk bahwa produk mereka halal dan layak dipasarkan di Indonesia.

e) Threat to Image, Reputation and High-priority Goals

Tentu saja secara otomatis adanya krisis yang muncul akan menyebabkan turunnya reputasi atau image perusahaan. Namun bila dapat ditangani dan diselesaikan dengan strategi komunikasi yang baik, hal ini justru akan meningkatkan reputasi pada perusahaan tersebut.

5. Strategi Komunikasi

Strategi komunikasi yang dilakukan BreadTalk menanggapi masalah belum adanya label halal terhadap produk yang dipasarkan mereka di Indonesia terkesan sangat pasif. Karena belum adanya klarifikasi langsung dari pihak BreadTalk tentang usaha untuk mendapatkan sertifikat halal dari MUI. 
6. Image Restoration Theory dan Situational Crisis Theory

a) Image Restoration Theory

- Strategi menyangkal (denial)

Strategi ini merupakan penyangkalan organisasi atau perusahaan telah melakukan kesalahan dan pernyataan bahwa organisasi atau perusahaan tidak terlibat sebagai penyebab krisis tersebut.

- Strategi menghindari tanggung jawab (evasion of responsibility)

Organisasi atau perusahaan berusaha membatasi tanggungjawabnya pada suatu krisis.

- Strategi mengurangi serangan (reducing the offensiveness)

Secara umum bahwa organisasi atau perusahaan tidak menyangkal telah melakukan tindakan yang menyebabkan krisis. Dalam strategi ini, organisasi berupaya mengurangi dampak negatif dan berusaha memperbaiki turunnya citra positif.

Tindakan korektif (corrective actions)

- Melalui strategi ini, organisasi berusaha memperbaiki kerusakan dan berjanji untuk mencegah terjadinya pengulangan krisis.

Menanggung akibat krisis (mortification)

- Organisasi atau perusahaan menyatakan kesediaan untuk bertanggung jawab terhadap akibat krisis dan menyampaikan penyesalan serta permohonan maaf.

\section{b) Situational Crisis Theory}

- Evaluasi ancaman reputasi

Dalam hal ini mengevaluasi ancaman yang ditimbulkan oleh krisis tersebut terhadap reputasi perusahaan.

- Merekomendasikan strategi penanganan krisis yang tepat.

Memilih strategi yang tepat sesuai dengan kondisis atau level krisis yang sudah terjadi.

- Strategi menyangkal (denial)

Strategi ini merupakan penyangkalan organisasi atau perusahaan telah melakukan kesalahan dan pernyataan bahwa organisasi atau perusahaan tidak terlibat sebagai penyebab krisis tersebut.

- Strategi mengurangi serangan (reducing the offensiveness)

Secara umum bahwa organisasi atau perusahaan tidak menyangkal telah melakukan tindakan yang menyebabkan krisis. Dalam strategi ini, organisasi berupaya mengurangi dampak negatif dan berusaha memperbaiki turunnya citra positif.

- Tindakan korektif (corrective actions)

Melalui strategi ini, organisasi berusaha memperbaiki kerusakan dan berjanji untuk mencegah terjadinya pengulangan krisis.

- Potensi peluang

Krisis juga membawa potensi peluang, dimana krisis juga terdapat warna positif seperti : pembelajaran organisasi, komunikasi etis, retorika terhadap visi retrospektif, retorika organisasi efektif.

\section{METODE PENELITIAN}

Metode penelitian yang digunakan adalah metode penelitian deskriptif kualitatif dengan menggunakan studi dokumentasi yang diperoleh dari kumpulan beberapa wacana yang terkait dengan pemberitaan BreadTalk yang terdapat pada beberapa portal media online.

Metode ini lebih menekankan pada eksplorasi mendalam tentang cara pandang publik atau masyarakat dalam memahami kehidupan sosial mereka melalui bahasa, suara, gaya pribadi dan kegiatan sosial.

\section{PEMBAHASAN}

\section{a. Sertifikat Halal}

Sertifikat Halal MUI adalah fatwa tertulis Majelis Ulama Indonesia yang menyatakan kehalalan suatu produk sesuai dengan syariat Islam. Sertifikat Halal MUI ini merupakan syarat untuk mendapatkan ijin pencantuman label halal pada kemasan produk dari instansi pemerintah yang berwenang. 


\title{
b. Tujuan Sertifikasi Halal
}

Sertifikasi Halal MUI pada produk pangan, obat-obatan kosmetika dan produk lainnya dilakukan untuk memberikan kepastian status kehalalan, sehingga dapat menenteramkan batin konsumen dalam mengkonsumsinya. Kesinambungan proses produksi halal dijamin oleh produsen dengan cara menerapkan Sistem Jaminan Halal.

Sesuai dengan yang diatur dalam kriteria sistem jaminan halal (SJH) LPPOM MUI, setiap pelaku usaha harus menjamin tidak adanya kontaminasi silang dengan bahan atau produk yang haram atau najis.

Berdasarkan pasal 21 UU JPH bahwa lokasi, tempat, dan alat proses produk halal sebagaimana wajib dijaga kebersihan dan higienitasnya, bebas dari najis dan bebas dari bahan tidak halal. Sebaiknya, masyarakat jeli dalam memilih produk. Sekaligus, pelaku harus usaha cepat tanggap terhadap setiap permasalahan di masyarakat.

BreadTalk belum memiliki sertifikasi halal MUI untuk saat ini. Sebelumnya toko roti ini pernah memiliki sertifikasi halal, tapi tidak diperpanjang, karena tidak memenuhi Sistem Jaminan Halal LPPOM MUI.

\section{c. Klarifikasi MUI Mengenai Sertifikasi Halal}

Klarifikasi yang dibeberkan pada tiga tahun lalu itu, kurang menjadi bukti kuat yang menyatakan kalau BreadTalk tidak halal. Bisa saja sudah melakukan perpanjangan, namun banyak publik yang belum tahu.

Pihak BreadTalk pernah mengkonfirmasi hal itu melalui balasan komentar di Instagram, media sosial milik BreadTalkyaitu@breadtalkindo.

\begin{abstract}
“@ochataya Dear Customer, kami informasikan bahwa seluruh bahan baku produk yang digunakan di BreadTalk Indonesia adalah halal dan tidak menggunakan bahan-bahan yang mengandung alcohol, babi, atau bahan-bahan non halal lainnya dalam proses pembuatan produk-produk kami. Selain itu, kami mensyaratkan kepada seluruh supplier kami wajib memiliki sertifikat halal dan memastikan bahwa hanya menggunakan bahan baku yang bersertifikat halal. Terima kasih".
\end{abstract}

Hingga saat ini, belum ada klarifikasi lebih lanjut tentang masa berlaku sertifikat halal yang dipunyai perusahaan tersebut. Baik dari toko roti itu sendiri, maupun dari MUI. Pernyataan dari pihak BreadTalk tersebut merupakan implementasi dari Teori Image Restoration dalam komunikasi krisis. Teori Image Restoration dalam komunikasi krisis didefinisikan sebagai usaha menjaga nama baik perusahaan dengan memperbaiki citra dan reputasi perusahaan yang terancam di mata publik. (Kriyantono, 2014).

Direktur LPPOM MUI, Dr. Ir. Lukmanul Hakim menegaskan kepada masyarakat untuk bisa lebih jeli dalam mengkonsumsi sebuah produk dan jangan mudah percaya dengan sebuah berita yang kebenarannya masih terombangambing.

Sangat disayangkan ketika produk sebesar itu tidak memperhatikan dampak apa yang akan didapatkan perusahaan tersebut setelah mengambil sebuah keputusan untuk tidak memperpanjang sertifikat halal yang tentunya memunculkan keraguan konsumen untuk membeli produk BreadTalk.

\section{d. Tahapan Komunikasi Krisis}

Ada tiga kondisi yang umum terjadi dalam krisis. Menurut Argenti (2009: 259), hal tersebut adalah: (1) elemenelemen yang sifatnya tak terduga; (2) informasi yang tidak mencukupi; dan (3) begitu cepatnya dinamika yang terjadi. Sementara Millar \& Heath (2004) berpendapat bahwa dalam situasi krisis berita bisa menyebar begitu cepat yang berpotensi melumpuhkan jajaran manajemen sebelum mereka bisa mengontrol situasi dengan efektif. Untuk menjaga citra positif, sebuah korporasi harus menciptakan langkah yang cepat dan efektif saat menghadapi problem apapun, sebab krisis bisa merusak citra paling positif dari sebuah organisasi yang sudah mapan sekalipun.

Dalam kasus krisis ini BreadTalk melakukan tahapan - tahapan dalam menangani kasus krisis tersebut, tahapan tahapan krisis yang dilakukan adalah :

\section{Pre Crisis}

Tahapan ini merupakan kondisi sebelum krisis muncul dan telah ada benih krisis sebelumnya namun belum terdeteksi yaitu pada awalnya BreadTalk telah mendapatkan sertifikasi halal, namun sertifikasi halal tersebut hanya berlaku sampai tanggal 28 Agustus 2015.

\section{Tahap Warning}

Pada tahapan ini barulah muncul masalah krisis, yaitu BreadTalk yang sertifikat halalnya sudah berakhir belum diperpanjang hingga saat ini dan BreadTalk belum melakukan perpanjangan sertifikasi tersebut.

\section{Tahap Acute Crisis}

Pada tahapan ini krisis sudah mulai diketahui oleh media dan masyarakat. Dimana berita mengenai BreadTalk yang tidak memiliki sertifikat halal ini telah tersebar di media online dan offline. Hal ini sangat 
berdampak pada omzet penjualan BreadTalk yang mengalami penurunan, bahkan ditemukan pula beberapa gerai BreadTalk tutup.

\section{Tahap Clean Up}

Tahap ini merupakan tahapan dimana perusahaan memulihkan diri dari kerugian dan coba menyelamatkan reputasi. Pada tahapan ini perusahaan ini memberikan penjelasan bahwa sebelumnya BreadTalk telah memiliki sertifikat halal dari MUI namun memang sudah berakhir masa berlakunya dan belum diperpanjang. Selain itu pihak BreadTalk memberikan pernyataan pula bahwa BreadTalk menggunakan bahan - bahan yang halal, hanya saja belum tersertifikasi oleh MUI.

\section{Tahap Post Crisis}

BreadTalk berusaha untuk memenangkan kembali kepercayaan publik dengan beberapa cara diantaranya adalah dengan memberikan keterangan bahwa pada saat ini mereka sedang menjalani proses perpanjangan sertifikasi halal ke LPPOM MUI. Selain itu BreadTalk juga secara berkala memberikan promo - promo menarik kepada pelanggannya.

\section{KESIMPULAN}

Krisis dapat terjadi kapan saja pada sebuah perusahaan. Krisis yang terjadi dapat berdampak pada reputasi perusahaan apabila tidak ditangani dengan baik. Kasus komunikasi krisis yang terjadi pada BreadTalk ini memberikan contoh bahwa krisis yang tidak ditangani dengan baik dapat mengakibatkan kerugian dan memperburuk citra perusahaan sehingga beresiko kehilangan kepercayaan dari konsumen. Meskipun pada akhirnya BreadTalk dapat mengatasi krisis tersebut, akan tetapi BreadTalk telah terlebih dahulu kehilangan kepercayaan konsumen dan butuh waktu yang tidak sedikit untuk memulihkan kembali hal tersebut.

\section{DAFTAR PUSTAKA}

Argenti, Paul A. 2009. Corporate Communication, Fifth Edition. New York: McGraw Hill

Coombs, Timothy W. 2006. “Crisis Management : A Communicative Approach.” Public Relations Theory II. Carl H. Botan \& Vincent Hazelton (eds.). Mahwah : Lawrence Erlbraum Associates

Kriyantono, R. (2014). Teori Public Relations Perspektif Barat dan Lokal. Jakarta: Kencana PrenadaMedia Group.

Kyhn, Helene Stavem. 2008. Situational Crisis Communication Theory: Its Use in A Complex Crisis with Scandinavian Airlines' Grounding of Dash 8-Q400 Airlines. Master Thesis. Aarhus School of Business. http://pure.au.dk/portalasbstudent/files/3900/Helene_Stavem_Kyhn__Master_Thesis.pdf,

Millar, Dan Pyle. \& Heath, Robert Lawrence (ed). 2004. Responding to crisis: a rhetorical approach to crisis communication. Mahwah, New Jersey: Lawrence Erlbaum Associates. 